\title{
Predicting Epilepsy after Blunt Head Injury*
}

\author{
W. BRYAN JENNETT, $†$ M.D., F.R.C.S.
}

Brit. med. F., 1965, 1, 1215-1216

Epilepsy occurs in rather less than $10 \%$ of patients admitted to hospital after a blunt head injury. The problem posed by a rather uncommon complication of a very common condition is to know which few patients, of the many at risk, are likely to develop it. If they could be recognized soon after injury, prophylactic anticonvulsants could be prescribed, different advice might be given about resettlement, and their lawyers could be advised to take the risk of epilepsy into account in assessing damages.

The possibility of making a reliable prediction of epilepsy was explored by studying a series of head injuries prospectively and by investigating a number of patients with established traumatic epilepsy. The methods have been described in detail elsewhere with full statistical analysis (Jennett, 1962). The study was limited to non-missile head injuries admitted to hospital.

While investigation of the influence of various factors on the incidence of epilepsy was based on a large series of cases from Oxford, Cardiff, and Manchester, estimation of the absolute overall incidence of epilepsy was based solely on 1,000 consecutive admissions to the Accident Service of the Radcliffe Infirmary, Oxford. All patients with even brief amnesia after head injury were admitted to the service, which was the only one in the district. This series was therefore a relatively unselected one and included a high proportion of mild injuries compared with admissions to an average hospital ; the figure of $10 \%$ for the incidence of epilepsy is probably rather low on this account.

Epilepsy was accepted as traumatic if one or more fits followed an injury in a patient with no previous history of epilepsy and in whom there was no other apparent cause for fits at the time or during subsequent follow-up ; most cases were followed for more than two years after their first fit without any evidence of coincidental organic brain disease emerging to account for the epilepsy.

It might be claimed that some suffered from idiopathic or cryptogenic epilepsy of late onset. Only five cases of idiopathic epilepsy would have been expected to appear during the period of observation in the group of patients followed up, taking account of their ages (College of General Practitioners, 1960). In fact over 350 patients had the first fit of their lives during this time.

\section{Early Epilepsy}

Epilepsy was defined as early if it occurred within a week of the injury; it was unusual for the first fit to appear between the end of the first week and the twelfth week after injury (Jennett and Lewin, 1960).

Early epilepsy is apt to be dismissed as of no significance, and certainly it is of little immediate importance, except when there is status epilepticus, which may threaten life.

In particular early epilepsy is probably never the sole sign of a developing intracranial haematoma, although a fit may sometimes be mistaken for acute cerebral compression due to a clot. For example, a patient who was previously alert with

* Read to the B.M.A. Annual Clinical Meeting, Stoke-on-Trent, 1963. + From the Glasgow and West of Scotland Neurosurgical Unit and the
University of Glasgow. normal reacting pupils may be found to be unrousable, with fixed dilated pupils; a recent epileptic episode may account for this state but may have escaped notice either because there was no classical convulsion or because the fit was not witnessed. Such a patient may be taken urgently to the operating-theatre for burr-holes while still in this post-ictal state and may even have an emergency tracheostomy performed; but more often the rapid return of consciousness reveals the true nature of the incident.

The real significance of early epilepsy is that it increases by about four times the chance of epilepsy developing later (Table I). This applies even if there has been only a single fit in the

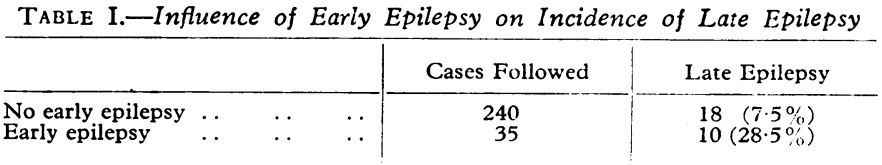

first week, and no matter how severe or trivial the injury. There is one exception- "immediate" epilepsy, when a generalized convulsion occurs within a minute of an injury, usually a trivial one. Such an episode seems not to predispose to late epilepsy and may perhaps represent a form of reflex epilepsy which does not recur without the specific stimulus.

\section{Late Epilepsy}

Estimates of the incidence of late epilepsy will depend in part on how long patients are followed up after injury. Confining the study to those followed for at least four years after injury, $5 \%$ were found to have epilepsy more than a week after the injury; some had already had early epilepsy, and about $1.5 \%$ of the total series of injuries had epilepsy both in the first week and then again later (Table II). This overall figure of $5 \%$ of

$\begin{array}{ccccc}\text { TABLE II.-Incidence of Epilepsy } & \text { After } & \text { Injury } \\ \text { Early epilepsy (first week) } & \ldots & \ldots & 5 \% \\ \text { Late epilepsy } & \ldots & \ldots & \ldots & 5 \% \\ \text { Both early and late } & \ldots & \ldots & \ldots & 1.5 \% \\ \text { Epilepsy at some time after injury } & \ldots & 8.5 \%\end{array}$

injury cases developing late epilepsy is of little value in assessing the risk in an individual case because when groups of patients who have suffered different types of injury and early complication are followed, the epilepsy rate is found to vary considerably with certain factors.

Early epilepsy has already been mentioned as predisposing to late epilepsy in $25 \%$, whatever the type of injury. Acute intracranial haematoma was associated with a similar risk, regardless of the severity of the initial injury or whether there had been early epilepsy. The duration of the post-traumatic amnesia and the presence of depressed fracture have complex effects on the incidence of epilepsy, which must be discussed more fully.

\section{Post-traumatic Amnesia (P.T.A.)}

Severity of injury, as judged by the P.T.A., appeared to increase the risk of late epilepsy (Table III). This association was much more striking in patients who had suffered a 
depressed fracture (see Table VIII); if these were excluded there was no significant difference in the epilepsy rate whether the P.T.A. had lasted for less or more than 24 hours (Table IV). Neither did prolonged amnesia increase the incidence of epilepsy in patients already predisposed by virtue of having suffered early epilepsy or an intracranial haematoma. In patients with

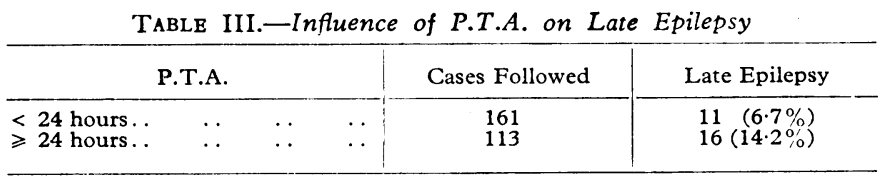

TABLE IV.-Injuries Without Depressed Fracture

\begin{tabular}{|c|c|c|c|c|}
\hline \multicolumn{3}{|c|}{ P.T.A. } & \multirow{2}{*}{ 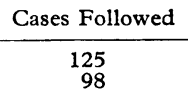 } & \multirow{2}{*}{$\begin{array}{c}\text { Late Epilepsy } \\
8(6 \cdot 4 \%) \\
9(9 \cdot 2 \%)\end{array}$} \\
\hline $\begin{array}{l}<24 \text { hours } . \\
\geqslant 24 \text { hours } .\end{array}$ & $\ldots$ & $\begin{array}{ll} & \ldots \\
\ldots & \end{array}$ & & \\
\hline
\end{tabular}

TABLE V.-Injuries Without Early Epilepsy, Depressed Fracture, or

\begin{tabular}{|c|c|c|c|c|c|}
\hline \multicolumn{6}{|c|}{ Haematoma } \\
\hline \multicolumn{4}{|c|}{ P.T.A. } & Cases Follcwed & Late Epilepsy \\
\hline $\begin{array}{l}<24 \text { hours .. } \\
\geqslant 24 \text { hours } . .\end{array}$ & $\ldots$ & $\ldots$ & $\therefore$ & $\begin{array}{r}100 \\
68\end{array}$ & $\begin{array}{l}1(1 \%) \\
1(1.5 \%)\end{array}$ \\
\hline
\end{tabular}

neither of these complications, nor a depressed fracture, the incidence of epilepsy was extremely low, even when P.T.A. was prolonged (Table V).

\section{Depressed Fracture}

Depressed fracture is the one factor which has always been assumed to predispose to epilepsy after injury. The present series appeared to support this assumption, but only when all the depressed fractures were considered as a whole (Table VI).

\begin{tabular}{|c|c|c|c|}
\hline & & Cases Followed & Late Epilepsy \\
\hline $\begin{array}{l}\text { No depressed fracture } \\
\text { Depressed fracture }\end{array}$ & $\begin{array}{ll}\ldots & \ldots \\
\cdots & \cdots\end{array}$ & $\begin{array}{r}223 \\
52\end{array}$ & $\begin{array}{l}17(7 \cdot 6 \%) \\
11(21 \cdot 1 \%)\end{array}$ \\
\hline
\end{tabular}

TABLE VII.-Influence of Early Epilepsy on Late Epilepsy After
Depressed Fracture*

* Larger series than in Table VI.

TABLE VIII.-Influence of P.T.A. on Late Epilepsy After Depressed Fracture*

\begin{tabular}{ccc|cc|c}
\hline \multicolumn{3}{c|}{ P.T.A. } & & Cases Followed & Late Epilepsy \\
\hline$<24$ hours $\ldots$ & $\ldots$ & $\ldots$ & $\ldots$ & 37 & $4(10.6 \%)$ \\
$\geqslant 24$ hours.. &. & $\ldots$ &. & 21 & $12(57 \%)$ \\
\hline
\end{tabular}

* Larger series than in Table VI.

TABle IX.-Injuries Without Early Epilepsy or Prolonged P.T.A.

\begin{tabular}{|c|c|c|c|c|}
\hline & & & Cases Followed & Late Epilepsy \\
\hline $\begin{array}{l}\text { No depressed fracture } \\
\text { Depressed fracture }\end{array}$ & $\begin{array}{l}\ldots \\
\cdots\end{array}$ & $\because$ & $\begin{array}{r}112 \\
32\end{array}$ & $\begin{array}{l}4(3.6 \%) \\
1(3.1 \%)\end{array}$ \\
\hline
\end{tabular}

When other factors were taken into account the relation proved to be more complex. Late epilepsy was much more common when a depressed fracture was associated with early epilepsy or prolonged P.T.A. (Tables VII and VIII) and in such predisposed patients the likelihood of epilepsy was still further increased if the dura was penetrated. On the contrary, only one patient developed late epilepsy out of 32 with a depressed fracture uncomplicated by prolonged P.T.A. or an early fit, including some with dural penetration (Table IX). More than half of all the depressed fractures in the unselected series of head injuries were of this uncomplicated kind, in which the incidence of epilepsy was no greater than in similar injuries without a depressed fracture.

\section{Time of Onset of Epilepsy}

About $50 \%$ of patients who developed late epilepsy had their first fit within the first year after injury, but more than $25 \%$ began to have epilepsy more than four years after injury. The longer a patient survives without a fit the less his chances of having epilepsy as a result of his injury. The altered risk at the end of the first year, provided there has been no epilepsy since the first week, is given by the formula:

$$
R_{1}=\frac{\frac{1}{2} R_{0}}{100-\frac{1}{2} R_{0}} \times 100
$$

where $R_{1}$ is the percentage risk at the end of the first year and $R_{0}$ is the original risk. For small risks $(<10 \%) R_{1}$ approximates to $\frac{1}{2} R_{0}$, but as the original risk increases so does $R_{1}$ become increasingly greater than $\frac{1}{2} R_{0}$-for example, an $R_{0}$ of $60 \%$ is reduced only to $44 \%$ at the end of the first year.

The $50 \%$ onset within a year is an average for all types of injury; late epilepsy after intracranial haematoma, or when there has already been early epilepsy, is more likely to appear within the year, and after depressed fracture and prolonged P.T.A. is more often delayed beyond the first year.

\section{Conclusions}

The incidence of epilepsy after a blunt head injury ranges from $1 \%$ to over $50 \%$, according to the nature of the injury and the early complications. Only if there is accurate information about these factors can a reliable prediction be made of the risk in the individual patient.

There would seem to be a case for giving prophylactic anticonvulsants for at least a year to those patients in whom the risk of epilepsy is substantial (Table X).

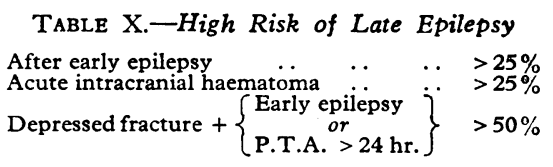

\section{Summary}

Epilepsy occurs in rather less than $10 \%$ of blunt head injuries admitted to hospital. The risk of epilepsy varies greatly with the nature of the injury and early complications; this varying risk is explored by a statistical analysis of a large series of injuries.

Early epilepsy, within a week of injury, occurs in about $5 \%$ of cases. It does not indicate immediate intracranial complications, but it is followed by late epilepsy in over $25 \%$ of cases.

Late epilepsy is equally frequent $(>25 \%)$ when there has been an acute intracranial haematoma. Neither depressed fracture nor prolonged post-traumatic amnesia alone predisposes to late epilepsy, but when they occur together are associated with a high risk of epilepsy. Half the patients with late epilepsy suffer their first fit within a year of injury.

Tables I, III, V, VI, VII, VIII, and IX are reproduced with the permission of Heinemann Medical Books Ltd.

\section{REFERENCES}

College of General Practitioners (1960). Brit. med. f., 2, 416.

Jennett, W. B. (1962). Epilepsy After Blunt Head Injuries. Heinemann, London.

and Lewin, W. S. (1960). F. Neurol. Neurosurg. Psychiat., 23, 295. 